Pre-proof, Space Policy, 27.4 (2011).

\title{
Property rights and the duty to extend human life
}

Tony Milligan

\begin{abstract}
This article examines what the author calls the argument from duty, i.e. the argument that we should recognize private property rights in space because doing so will help us to act upon our duty to ensure the future survival of humanity. More strongly, the motivational impact of recognizing such rights may be required if we are to act upon this duty in an effective manner. The author argues that the duty in question is important but not over-riding and that there are other duties with which it may happen to conflict. More specifically, the practical requirements of human resettlement may conflict with our duty to pursue a more just and environmentally-sensitive way of living here on Earth. If this is correct, only a significantly-weakened argument from duty may be made. It also strengthens the case for thinking about our duties in the light of other ethical considerations.
\end{abstract}

\section{Introduction}

It is tempting to say that 'nobody owns the Moon', that even well-motivated treaties (the

Outer Space Treaty or the Moon Agreement) which, on the majority interpretation, claim it protectively as the common heritage of mankind are slightly askew. It is, after all, doubtful that we could mount a sensible defence of a shared human entitlement to exclusive possession against the claims and vital interests of any other party (if such another party happened to exist). The most we might say is that the Moon is comparatively close to us and that it impacts daily upon our lives. Perhaps this would give us strong grounds for claiming 
that it should not be meddled with but it is not obvious that proximity and impact would justify the claim that we own it and that others do not.

Conveniently, the claim of shared human ownership is not made to forestall nonhuman meddling. It is, rather, a way of saying 'no' to claims that any portion of the Moon might become the private property of an individual or of a restricted group of individuals (those belonging to a nation-state, group of states or corporate interest). We, or at least some of us, are the ones against whom the cautionary legal claim of shared ownership is advanced. ${ }^{1}$

\section{The argument from duty}

Notwithstanding this, there is significant support for an extension of private property rights off-world, support that draws not only upon a sense of realpolitik and the belief that 'this is probably going to happen anyway', but also draws upon an intuitively appealing argument that seeks to justify rather than merely predict. $^{2}$

With variations, the argument runs as follows: We have a duty to secure the future survival of humanity (to extend human life). Ultimately this can only be done by spreading it elsewhere. As a step towards this we need to develop efficient and repeatable ways to get out of the Earth's atmosphere. We need to begin to explore the nearby region of space. We have an opportunity to do so now but it is by no means clear that the window of opportunity will remain open indefinitely. The technological and political preconditions may not always be in place, the window may turn out to be far smaller than we may imagine, it could be measured in centuries rather than millennia. We therefore have a duty to exploit our present opportunity. This may best be done (and perhaps it may only be done) by promoting the kind of incentives that will encourage the private sector to invest heavily in space. This, in turn, 
requires us to allow, recognize and (as far as possible) enforce, private property rights with regard to non-artefacts. Initially this should involve recognition of private property with regard to sub-lunar and sub-planetary sized objects (the weak conclusion) but ultimately such rights will have to be extended to claims upon lunar and planetary real estate (the strong conclusion).

Let us call this the argument from duty. While it may not correspond exactly to the position of any one individual it nonetheless paraphrases what has lately been maintained and not, in its entirety, rejected. It includes some temporal indexing on the basis that, without such indexing we might as well wait it out for a century or two. ${ }^{3}$ Optionally, it could be accompanied by an acknowledgement of the need for a code of ethics to allay fears about the potential misuse of resources. ${ }^{4}$ Nuances of this sort may change from formulation to formulation but the gist remains the same. ${ }^{5}$

It is worth noting that the argument supports private property rights on instrumental and, in a sense, pragmatic grounds. It does so without any direct or hidden appeal to an entitlement (or natural entitlement) that is based solely upon the actions of individual agents or upon the actions of their representatives. What I have in mind here is flag-planting, claim staking, first occupancy, or the mixing of what is owned (bodily effort) with what is not-yetowned (land, regolith, and so on). There is no problematic appeal to a type of action that, in the eyes of any reasonable agent or committee of such agents, would automatically transform objects into private property. Considerations of the latter sort, associated particularly with classic accounts of property stemming from John Locke, may happen to provide a useful way to legitimate claims once the institution of private property is up and running, but they do not legitimate the institution itself. (Anyone who comes up with such a legitimation on Lockean grounds should be sure to let someone else know.) ${ }^{6}$ 
Even so, pragmatically driven as it is, we may still be worried that if the argument from duty proves anything at all then it proves too much. It makes a case for rights which many of us are reluctant to grant and so, we may suspect, some of its assumptions or the passage from the latter to the conclusion, leads us astray. So let us focus upon the case that it makes for the weak conclusion, that some property rights should be granted in non-terrestrial real estate, for example rights with regard to mineral-rich asteroids, rather than any case that it makes for the strong conclusion concerning property rights on larger bodies. In any case, if the argument to the former fails then the argument to the latter must also fail. But once we are in the business of restricting our conclusions it may be tempting to suggest that licensed extraction rights alone should be enough to promote the relevant incentives and that there is no need for the recognition of private real estate in any form. ${ }^{7}$ Tempting though this option is, it may turn out to be slightly over-optimistic. While there will be a very big payoff for mineral extraction for someone at some point in time, the relevant technology will require massive, speculative (and for some, completely wasted) investment over an extended period of time and without any significant short-term payback. If we are to entice the private sector into thinking this big and this long we may have to offer at least the kind of transferrable security that it prefers.

For similar reasons we may set aside interesting kinds of scepticism about the very idea of private property and about its applicability off-world. What matters is not the reality of ownership to the exclusion of the claims of all others but rather the historically-sanctioned semblance of such exclusivity. Put crudely, what matters is the sheer fact that the private sector happens to like legally-recognized property rights even if, upon closer examination, the rights in question are not all that they appear. 


\section{A provisional look at background assumptions}

While the argument from duty does not appeal to any deep metaphysical assumptions about how objects first become private property it does appeal to other assumptions that may be just as open to question. Not the least of these is the claim that the private sector can deliver and that it can do so where state-controlled programmes have failed or where they have been, and are likely to remain, sluggish. There is currently a widespread belief that it can do so, based partly upon the private sector's first tentative steps into space and partly upon the hope that after the Space Shuttle something a little more ambitious may emerge.

While enthusiastic about space exploration I am sceptical about this belief and I am not alone in my scepticism. ${ }^{8}$ But it could be misplaced. Nobody needs to be a free-market enthusiast, an Elon Musk or Peter Diamandis, before they can accept that there may sometimes be advantages that only the private sector can provide. The private sector may be able to deliver not because the market is always best but because, as a matter of dumb luck and circumstance, it sometimes happens to be geared to do the right things at the right time. The claim that now is one of these occasions is an empirical claim of a sort that need not be embedded in any larger theory about the overall virtues of private enterprise. It is also a claim that could be right.

A rather different, but even more basic, assumption upon which the argument from duty depends is that there really is a duty to extend human life, a duty to ensure that when things go badly wrong here on Earth, there will still be humans alive somewhere else. No doubt most of us are not misanthropes and would prefer that humanity does continue, in some acceptable form, but preferences aren't duties although they may sometimes be symptomatic of the existence of the latter. In this instance I am prepared, even inclined, to accept that our ordinary preferences are symptomatic in the relevant way and that the duty to extend human 
life is just as real as any other duty. ${ }^{9}$ But even if this is correct it does not automatically follow that there an overriding duty, one which clears the field and does not (or cannot) conflict with duties of any other sort. ${ }^{10}$ It would, after all, be more than a little fanatical to suggest that we have a duty to extend human life by any means necessary and at whatever expense. Claims of the latter sort ultimately lean upon dubious appeals to human destiny or upon an attitude that is not simply anthropocentric but which may border on a species fanaticism. Awkwardly, if the interests of preserving the species trump everything else then they must trump the interests of all the individual humans who make up the species and who may then be regarded as vehicles for its survival. This kind of dedication to humanity, rather than to humans, is something that we can probably do without.

However, once the assumption that we have a duty to extend human life is reined in a little, the conclusion of the argument from duty (as well as one of its key assumptions) has to be restated. I would suggest that as a revised version of the weak conclusion, something of the following sort would be appropriate: We have at least some (defeasible) duty-based reasons to recognize and (as far as possible) enforce, private property rights with regard to sub-lunar and sub-planetary sized objects. With matters formulated in such modest terms, the argument becomes less straightforward but more plausible.

\section{The direction and limits of duty}

The duty to extend human life (however real and however important) provides us only with defeasible reasons for acting. Other considerations, and perhaps other duties, might come into conflict with it. I will suggest that such rival considerations need not always be duties to individual humans. Were we to reinstate the strong conclusion and favour lunar or planetary real estate the possibility of a different kind of conflict would become clear. On the 
one hand we would have a duty to extend human life and on the other we would have a duty towards other worlds. At a push I'd formulate the latter as a duty concerning the integrity of pristine environments (a formulation that leaves some work to be done in order to explain exactly what is 'pristine' about them). The duty in question is precisely what the protective aspect of current agreements is sensitive to. But even when we stick with the weak conclusion concerning sub-lunar and sub-planetary property rights, a plausible case can still be made for the existence of duties that clash because they direct our actions in ways that are incompatible.

Suppose, for example, we say that we have an obligation to pursue a more just and environmentally-sensitive way of living. This could well be seen as a rival duty for a number of reasons. In the absence of unimagined technologies, manned or unmanned journeys beyond the solar system in order to extend human life would require nuclear technology. Even the more restricted ambition of sustainable resettlement within the solar system would probably require at least low-level human genetic modification of humans together with the genetic modification of non-human creatures placed in situ. We (humans and non-humans) are not made for all places and all times. Everywhere else is inhospitable. And should we be prepared to accept genetic modification of creatures (human and non-human) we would then also have to accept animal experimentation, at least during the (presumably extended) development stage for the biotechnology in question. It is not the kind of thing that we could do without the use of 'living systems'. (Perhaps smarter beings could do so, but we can't.) And here, with each step, we seem to be entering into deeper and progressively more troubleinfested waters.

This is not to say that any of these considerations (individually or as a cluster) give us a knock-down argument against human resettlement or against private property as a means to help bring it about. I do not think that there is any such knock-down argument. In the face of 
any conflicting duty it will always remain possible to appeal to our duty to extend humanity as 'in this instance' a 'greater duty'. (An intuition that not everyone will share.) My reason for focusing upon these particular issues (nuclear, GM and animal experimentation) is not that they silence rival considerations but simply that that they are issues which help to shape our attitude towards the limits of reasonable and defensible human control. Those who think there are no such limits will no doubt be unimpressed but others may be more open to the idea that our willingness to countenance restricting, and perhaps ultimately abandoning, some or all of these things may be a litmus test of an important sort. It could tell us whether or not we are genuinely willing to forgo at least some of the advantages of our best science in order to pursue a more just and environmentally-sensitive way of living.

As a clarification, I want to add that what is at stake here is not science versus environmental concern (which, after all, cannot reasonably do without science) but rather a clash between two significantly different ways of picturing our current predicament, two significantly different ways of making sense of the ethical responsibilities to which science, policy and environmental concern are answerable. On the one hand, there is a picture of our task as one of getting the job done, not only because we want to do it but because we recognize that we have a duty to do it or a greater duty to do it than we have to do anything else that we can think of. ${ }^{11}$ On the other hand, there is a messier picture in which we have more than one job to do, a picture of our predicament as something of a dilemma.

My claim that there is such a dilemma and that our predicament ought to be pictured in the messier way, presupposes that we do, after all, have a duty to extend human life. It also situates space ethics within a broader range of ethical concerns rather than regarding it as an attenuated or isolated discipline cast adrift from other instances of ethical deliberation. But this alone will not be enough to make the messier picture universally popular. Some may balk at the very idea of conflicting duties in the belief that human life is in some way structured to 
exclude any such possibility. Those more sympathetic to the possibility that duties may conflict (those who have read their Aeschylus and Sophocles and who know that such things can happen) may worry about the possibility of an ensuing paralysis. After all, if duty points in different directions how are we ever to justify acting in one way rather than another? The short answer is that, in our situation, no argument from duty can tell us all that we need to know and that considerations other than duty (although related to it) must be brought to bear. Such considerations may, again, be of a rough-and-ready pragmatic sort or they may be historic considerations about what we have done and have failed to do in the past.

As a rough and ready pragmatic consideration, it may be pointed out that if human resettlement could help to alleviate population pressures, and hence alleviate anthropogenic global warming, then this would count strongly in favour of meeting our duty to extend human life at the expense of other duties. But if, as seems likely, the time-scale for extensive resettlement is all wrong, if it could only be relevant to some distant and future environmental crisis rather than our own and present crisis, it will not weigh quite so heavily. (At least not as a here and now pragmatic matter.) As a more historic consideration, the fact that we have, for a long time, neglected our duties towards the non-human and have focused primarily (sometimes exclusively) upon human interests may weigh just as strongly in favour of accepting that our human-focused duties should not prevail. In that case, what will turn out to be decisive is something akin to a sense of restorative justice. In other circumstances, without such a historic imbalance, matters might be quite different. But what we must deal with are the circumstances in which we find ourselves and those that may reasonably ensue. 


\section{Conclusion}

So where does my revised way of picturing our predicament as dilemmatic leave us on the question of private property? Here, I want to suggest two things. Firstly, it does nothing to rule out the possibility of appeal to some other argument for private property rights that draws upon different assumptions about goals and obligations. Secondly, insofar as the case for private property rights is made by appeal to the argument from duty, it does leave us with a significantly-weakened case. The case is weakened not because the private sector cannot deliver all that the argument from duty assumes but weakened because, from an ethical point of view, the very thing that the argument uses in order to justify the extension of private property rights into space is a duty that we should act upon only with caution and, sometimes not at all.

\footnotetext{
${ }^{1}$ For cautionary concern about space resettlement see Marshall (1993, 1999); Sparrow (1999) and Macauley (2007). For a defence of the common heritage of mankind principle see Pop (2000).

${ }^{2}$ As an extreme example, Dinkin (2004) has suggested that we should circumvent existing international treaties through a system of pseudo-property, notionally under US state control. This would almost certainly involve violation of the treaties rather than favourable interpretation. Livingston (2003) presents a more measured case for free market activity. ${ }^{3}$ Cockell (2007), 173, shows a good appreciation that any plausible case for urgency about space exploration will require appeal to a potentially-restricted window of opportunity.

${ }^{4}$ For codes of ethics as part of a package of greater private sector involvement see Livingston (2003), Sachdeva (2010) and Williamson (2003). As a measure to ensure that such codes do not erect unwelcome barriers to space exploration, Williamson suggests that they should be shaped primarily by space professionals and by those who have direct experience of living in space.

${ }^{5}$ Cooper (2003), 116-117 writes about 'a duty to the ecosystem in order to preserve human life' and the gist of his position is pretty much a variant on what I have called the argument from duty. 'If we are to fulfil our duties to human and ecosystem alike by developing space, the current regime cannot stand. Private property rights are a means to motivate the development of space resources, provide equity, and supplement the limited resources of Earth's ecosystem'.

${ }^{6}$ Cooper (2003), 116, favours a broadly Lockean approach towards space property, on the basis that we are entitled to the fruits of our own labour. Lin (2006), 282, points out that the Lockean approach may be ethically compromised.
} 
${ }^{7}$ Jakhu \& Buzdugan (2008) argue that the current regulatory regime, including the common heritage of mankind principle, is not a barrier to resource exploitation and that property rights should remain restricted.

${ }^{8}$ Freedman (2011) gives a balanced account of the limits of existing private sector space programmes, the obstacles they face, and their more distant potential.

${ }^{9}$ For a robust defence of the existence of a duty to survive as a species see Schwartz (2011).

${ }^{10}$ Zubrin (1996) comes close to the view that our duty to extend human life is absolute and overriding. However, he qualifies the apparent anthropocentrism of this position by insisting that we have this duty because we are uniquely placed to extend life itself. Nevertheless, when given an actual choice between extending human life and safeguarding any indigenous microbacterial life-forms, Zubrin favours human life.

${ }^{11}$ The crux of the position developed in Cockell (2007) is that environmental concerns about the Earth and resettlement elsewhere are compatible. But Cockell focuses upon a restricted set of environmental concerns (particularly over-population, eco-technology and recycling). Schwartz (2011), 79-81, is even more dismissive of the idea of a real conflict of duties, largely on the basis of claims repeated from Cockell. McQuaid (2010) argues persuasively that NASA and policy makers have never quite come to grips with the tensions between environmentalism and space exploration and with the need to make sense of the latter that does justice to the former.

\section{Works Cited}

Cockell, Charles S. (2007). Space on Earth, (London: Macmillan).

Cooper, Lawrence A. (2003). "Encouraging space exploration through a new application of space property rights", Space Policy 19: 111-118.

Diedericks-Vershoor, L.H.P. (1999). An Introduction to Space Law, $3^{\text {rd }}$. edition, (The Hague: Kluwer Law International).

Dinkin, Sam. (2004). "Property Rights and Space Commercialisation", The Space Review, 10 May 2004.

Freedman, David H. (2011). "Jump-Starting the Orbital Economy”, Scientific American, December 2010.

Lin, Patrick. (2006). "Look Before Taking Another Leap for Mankind - Ethical and Social Considerations in Rebuilding Society in Space”, Astropolitics 4 : 281-294.

Livingston, David. (2003). "A code of ethics for conducting business in outer space", Space Policy 19: 93-4.

Macauley, Molly K. (2007). "Environmentally Sustainable Human Space Activities: Can Challenges of Planetary Protection be Reconciled", Astropolitics 5: 209-236. 
Marshall, Alan. (1999). "Gaining a share of the final frontier" in Brian Martin (ed.) Technology and Public Participation (Wollongong, Australia: Science and Technology Studies, university of Wollongong): 231-247.

Marshall, Alan. (1993). "Ethics and the Extraterrestrial Environment", Journal of Applied Philosophy, 10: 227-36.

McQuaid, Kim. (2010). "Earthly environmentalism and the space exploration movement, 1960-1990: A study in irresolution”, Space Policy 26: 163-173.

Pop, Virgiliu. (2000). "Appropriation in outer space: the relationship between land ownership and sovereignty on the celestial bodies", Space Policy 16: 275-282.

Jakhu, Ram. and Buzdugan, Maria. (2008). "Development of the Natural Resources of the Moon and Other Celestial Bodies:", Astropolitics 6: 201-250.

Sachdeva, Gurbachan Singh. (2010). "New Ethics for Space Commerce”, Astropolitics 8: 49-61.

Schwartz, James. S.J. (2011). "Our Moral Obligation to Support Space Exploration”, Environmental Ethics 33: 67-88.

Sparrow, Robert. (1999). “The Ethics of Terraforming”, Environmental Ethics 21: 227-45.

Williamson, Mark. (2003). "Space ethics and the protection of the space environment", Space Policy 19: 47-52.

Zubrin, Robert. (1996). The Case for Mars: The Plan to Settle the Red Planet and Why We Must, (Free Press: New York) 